\title{
Property of Equation Systems in Proportionally Restricted BLUP Using Canonical Transformation
}

\author{
Tsuyoshi TAKAHASHI*, Hiroaki IWAISAKI ${ }^{1}$ \\ and Yohji ITOH ${ }^{2}$ \\ Graduate School of Science and Technology, Niigata University. \\ Niigata-shi 950-2102 \\ ' Faculty of Agriculture, Niigata University, Niigata-shi 950-2102 \\ ${ }^{2}$ Office of Biostatistics, Otsuka Parmaceutical Co. Ltd., Chuo-ku, \\ Osaka-shi 540-0021
}

(Received September 1, 1997)

\begin{abstract}
In this paper, we describe how the procedure using canonical transformation for the restricted best linear unbiased prediction with the so-called zero restrictions considered (RBLUP CT) can be applied to the proportionally restricted best linear unbiased prediction of breeding values. Then we examine the property of simultaneous equation systems required in the presented procedure (PRBLUP CT) by investigating the ranks and the numbers of positive eigenvalues of the key matrices. Denoting the numbers of traits in the multi-trait animal model and the restricted traits by $q$ and $r$, respectively, it is shown that while in the RBLUP CT with zero restrictions the number of the independent equation systems is $q-r$, that in the PRBLUP CT becomes $q-r+1$. That is, as $r$ increases, the number of the independent equation systems to be solved decreases, and in the case of all traits restricted proportionally, for instance, the rank and the number of positive eigenvalues of the key matrix become unity and it is needed to solve only one system of the usual BLUP equations for the single transformed variable.

Anim. Sci. Technol. (Jpn.) 69 (4) : 321-325, 1998

Key words : Proportionally restricted BLUP, Canonical transformation, Rank, Multi-trait, Desired gain
\end{abstract}

Restricted selection is used to control genetic changes in some of traits to be improved. The theory of restricted selection index was formally presented by Kempthorne and Nordskog ${ }^{8)}$. The original index of Kempthorne and Nordskog allows maximum response to selection in certain traits, while keeping the change in other traits zero. The theory assumes known means and (co) variances of phenotypic records, unrelated candidates for selection, and no missing records. Indices with different types of restrictions were also considered by several researchers (for a review, e.g., see Brascamp $\left.{ }^{1}\right)$.

On the other hand, the best linear unbiased prediction (BLUP) of breeding values ${ }^{4.5)}$ is the viable alternative to the selection index approach and is applicable to more complicated data in animal breeding applications. Accordingly, the restricted best linear unbiased prediction (RBLUP) procedure, which is a BLUP counterpart of the restricted selection index, was derived by Quaas and Henderson ${ }^{10)}$. The RBLUP procedure generally requires the

* Present address : Hyogo Branch, Wagyu Cattle Registry Association, Chuo-ku, Kobe-shi 650 0004

Anim. Sci. Technol. (Jpn.) 69 (4) : 321-325 
system of simultaneous equations of relatively high order to be solved, and then an application of canonical transformation to RBLUP has also been proposed ${ }^{7}$. With the transformation technique, traits are transformed to be independent so that the equation system for each transformed variable is solved separately.

Restricted selection index and therefore RBLUP is known to be able to treat the more general case in addition to the case of the socalled zero restrictions. Mallard ${ }^{9)}$ showed that Kempthorne and Nordskog's restricted index can handle the case of proportional constraints, which was suggested by Kempthorne and Nordskog themselves ${ }^{8)}$. Moreover, Itoh and Yamada $^{6}$ presented the details of its property to handle proportional or desired gains.

Describing how the RBLUP method for zero restrictions using canonical transformation ${ }^{7)}$ (which will be referred to as RBLUP CT) can be applied to the case of proportional constraints imposed, the main purpose of this paper is to examine the nature of the current procedure, that is the proportionally restricted BLUP with canonical transformation used (denoted as PRBLUP CT), in the point of reducing the number of the transformed variables to be analyzed.

\section{Theory}

\section{Multi-trait animal model}

Assume that there are $q$ traits to be analyzed. The number of individuals to be evaluated is denoted by $p$ and the number of individuals with records by $n$.

For all $q$ traits, when observations are ordered by animals within traits, the multitrait animal model is written in matrix notation as

$$
\mathbf{y}=\left(\mathbf{I}_{q} \otimes \mathbf{X}\right) \boldsymbol{\beta}+\left(\mathbf{I}_{q} \otimes \mathbf{Z}\right) \mathbf{a}+\mathbf{e}
$$

with

$$
\begin{aligned}
& \mathbf{y}^{\prime}=\left[\begin{array}{llllll}
\mathbf{y}_{1}{ }^{\prime} & \mathbf{y}_{2}{ }^{\prime} & \cdots & \mathbf{y}_{i}{ }^{\prime} & \cdots & \mathbf{y}_{q}{ }^{\prime}
\end{array}\right] \\
& \boldsymbol{\beta}^{\prime}=\left[\begin{array}{llllll}
\boldsymbol{\beta}_{1}{ }^{\prime} & \boldsymbol{\beta}_{2}{ }^{\prime} & \cdots & \boldsymbol{\beta}_{i}{ }^{\prime} & \cdots & \boldsymbol{\beta}_{q}{ }^{\prime}
\end{array}\right], \\
& \mathbf{a}^{\prime}=\left[\begin{array}{llllll}
\mathbf{a}_{1}{ }^{\prime} & \mathbf{a}_{2}{ }^{\prime} & \cdots & \mathbf{a}_{i}{ }^{\prime} & \cdots & \mathbf{a}_{q}{ }^{\prime}
\end{array}\right],
\end{aligned}
$$

and

$$
\mathbf{e}^{\prime}=\left[\begin{array}{llllll}
\mathbf{e}_{1}^{\prime} & \mathbf{e}_{2}^{\prime} & \cdots & \mathbf{e}_{i}^{\prime} & \cdots & \mathbf{e}_{q}^{\prime}
\end{array}\right],
$$

where $\mathbf{y}_{i}$ is a vector of observations, $\boldsymbol{\beta}_{i}$ is a vector of unknown fixed effects, $\mathbf{a}_{i}$ is a vector of unknown random animal effects (breeding values), and $\mathbf{e}_{i}$ is a vector of randorn residuals for the $i^{\text {th }}$ trait, $\mathbf{X}$ and $\mathbf{Z}$ are incidence matrices and are assumed to be the same for all traits, $\mathbf{I}_{q}$ is the identity matrix of order $q \times q$, and $\otimes$ denotes the direct product operator.

We further suppose

$$
\mathrm{E}\left[\begin{array}{l}
\mathbf{y} \\
\mathbf{a} \\
\mathbf{e}
\end{array}\right]=\left[\begin{array}{c}
\left(\mathbf{I}_{q} \otimes \mathbf{X}\right) \boldsymbol{\beta} \\
0 \\
0
\end{array}\right] \text { and } \operatorname{Var}\left[\begin{array}{l}
\mathbf{a} \\
\mathbf{e}
\end{array}\right]=\left[\begin{array}{ll}
\mathbf{G} & \mathbf{0} \\
\mathbf{0} & \mathbf{R}
\end{array}\right]
$$

with $\mathbf{G}=\mathbf{G}_{0} \otimes \mathbf{A}$ and $\mathbf{R}=\mathbf{R}_{0} \otimes \mathbf{I}_{n}$, where $\mathbf{A}$ is the additive relationship matrix among animals to be evaluated, $\mathbf{G}_{0}$ and $\mathbf{R}_{0}$ are the additive genetic and residual variance-covariance matrices among traits, respectively, and $\mathbf{I}_{n}$ is the identity matrix of order $n \times n$.

\section{Proportionally restricted BLUP (PRBLUP)}

For the case of the RBLUP procedure with zero changes in some traits considered, when denoting the set of restrictions on a by $\mathrm{C}^{\prime} \mathbf{a}$ with $\mathbf{C}=\mathbf{C}_{0} \otimes \mathbf{I}_{p}, \mathbf{C}_{0}$ is as defined by Kempthorne and Nordskog ${ }^{8)}$ and whose elements are unity or zero.

Mallard $^{9)}$ demonstrated that the equations for proportional constraints can be converted in to those for zero restrictions on linear combinations of traits. For the case of proportional constraints, let the set of the constraints on a be $\mathbf{T}^{\prime} \mathbf{a}$ with $\mathbf{T}=\mathbf{T}_{0} \otimes \mathbf{I}_{p}$, assuming that the vector of relatively desired changes for traits 1 , $2, \cdots, r \leq q$ is $\mathbf{k}^{\prime}=\left[k_{1} k_{2} \cdots k_{r}\right]$. Then $\mathbf{T}_{0}{ }^{\prime}$ is given as $\left[\begin{array}{ll}\mathbf{T}_{r}{ }^{\prime} & \mathbf{0}^{\prime}\end{array}\right]$. The matrix $\mathbf{T}_{r}{ }^{\prime}$ is expressed, for instance, as

$$
\mathbf{T}_{r}{ }^{\prime}=\left[\begin{array}{ccccc}
\mathrm{k}_{2} & -\mathrm{k}_{1} & 0 & \cdots & 0 \\
\mathrm{k}_{3} & 0 & -\mathrm{k}_{1} & \cdots & 0 \\
\vdots & \vdots & \vdots & \ddots & \vdots \\
\mathrm{k}_{\mathrm{r}} & 0 & 0 & \cdots & -\mathrm{k}_{1}
\end{array}\right]
$$

such that

$$
\mathbf{T}_{r}^{\prime} \mathbf{k}=\mathbf{0} .
$$


Note that $\mathbf{T}_{r}$ is not unique and can be written in various forms ${ }^{6)}$.

Based on these facts, denoting the proportionally restricted best linear unbiased predictor by $\hat{\mathbf{a}}$, it is already known that a general form of the mixed model equations to be solved is straightforwardly written as

$$
\begin{aligned}
& {\left[\begin{array}{lll}
\mathbf{X}^{\prime} \mathbf{R}^{-1} \mathbf{X} & \mathbf{X}^{\prime} \mathbf{R}^{-1} \mathbf{Z} & \mathbf{X}^{\prime} \mathbf{R}^{-1} \mathbf{Z G T} \\
\mathbf{Z}^{\prime} \mathbf{R}^{-1} \mathbf{X} & \mathbf{Z}^{\prime} \mathbf{R}^{-1} \mathbf{Z}+\mathbf{G}^{-1} & \mathbf{Z}^{\prime} \mathbf{R}^{-1} \mathbf{Z G T} \\
\mathbf{T}^{\prime} \mathbf{G} \mathbf{Z}^{\prime} \mathbf{R}^{-1} \mathbf{X} & \mathbf{T}^{\prime} \mathbf{G} \mathbf{Z}^{\prime} \mathbf{R}^{-1} \mathbf{Z} & \mathbf{T}^{\prime} \mathbf{G} \mathbf{Z}^{\prime} \mathbf{R}^{-1} \mathbf{Z G T}
\end{array}\right]} \\
& {\left[\begin{array}{l}
\hat{\boldsymbol{\beta}} \\
\hat{\mathbf{a}} \\
\hat{\mathbf{v}}
\end{array}\right]=\left[\begin{array}{l}
\mathbf{X}^{\prime} \mathbf{R}^{-1} \mathbf{y} \\
\mathbf{Z}^{\prime} \mathbf{R}^{-1} \mathbf{y} \\
\mathbf{T}^{\prime} \mathbf{G} \mathbf{Z}^{\prime} \mathbf{R}^{-1} \mathbf{y}
\end{array}\right]}
\end{aligned}
$$

where $\hat{\beta}$ is a vector of some solution to $\beta$ and $\mathbf{v}$ is analogous to a vector of LaGrange multipliers.

\section{Proportionally restricted BLUP using ca- nonical transformation (PRBLUP CT)}

Eliminating $\hat{\mathbf{v}}$ from eq. (4) by absorption gives

$$
\left[\begin{array}{ll}
X^{\prime} H X & X^{\prime} H Z \\
Z^{\prime} H X & Z^{\prime} H Z+G^{-1}
\end{array}\right]\left[\begin{array}{l}
\hat{\beta} \\
\hat{a}
\end{array}\right]=\left[\begin{array}{l}
X^{\prime} H y \\
Z^{\prime} H y
\end{array}\right],
$$

where $\mathbf{H}=\mathbf{H}_{0} \otimes \mathbf{I}_{n}$, and

$$
\begin{aligned}
\mathbf{H}_{0}= & \mathbf{R}_{0}{ }^{-1}-\mathbf{R}_{0}{ }^{-1} \mathbf{G}_{0} \mathbf{T}_{0}\left(\mathbf{T}_{0}{ }^{\prime} \mathbf{G}_{0} \mathbf{R}_{0}{ }^{-1} \mathbf{G}_{0} \mathbf{T}_{0}\right)^{-1} \\
& \mathbf{T}_{0}{ }^{\prime} \mathbf{G}_{0} \mathbf{R}_{0}{ }^{-1} .
\end{aligned}
$$

Now, $\mathbf{G}_{0}$ is a positive definite matrix, and $\mathbf{H}_{0}$ is positive semi-definite. So, there exists a matrix $\mathbf{Q}$ which satisfies

$$
\mathbf{Q}^{\prime} \mathbf{G}_{0}^{-1} \mathbf{Q}=\mathbf{I}_{q} \text { and } \mathbf{Q}^{\prime} \mathbf{H}_{0} \mathbf{Q}=\mathbf{D} \text {, }
$$

where $\mathbf{D}$ is a diagonal matrix whose diagonal elements, $\lambda_{i}$, are the characteristic roots or the eigenvalues of the following equations

$$
\left|\mathbf{H}_{0}-\lambda \mathbf{G}_{0}^{-1}\right|=\mathbf{0} \text {. }
$$

With the positive $\lambda_{i}$, the mixed model equations to be solved are given as

$$
\left[\begin{array}{ll}
\mathbf{X}^{\prime} \mathbf{X} & \mathbf{X}^{\prime} \mathbf{Z} \\
\mathbf{Z}^{\prime} \mathbf{X} & \mathbf{Z}^{\prime} \mathbf{Z}+\mathbf{A}^{-1} \lambda_{i}{ }^{-1}
\end{array}\right]\left[\begin{array}{l}
\hat{\boldsymbol{\beta}}_{i}{ }^{*} \\
\hat{\mathbf{a}}_{i}{ }^{*}
\end{array}\right]=\left[\begin{array}{l}
\mathbf{X}^{\prime} \mathbf{y}_{i}{ }^{*} \\
\mathbf{Z}^{\prime} \mathbf{y}_{i}{ }^{*}
\end{array}\right],(9)
$$

where $\mathbf{y}_{i}{ }^{*}$ is obtained by $\left(\mathbf{Q}^{-1} \otimes \mathbf{I}_{n}\right) \mathbf{y}$. When $\lambda_{i}$ is zero, the equations become

$$
\left[\begin{array}{ll}
0 & 0 \\
0 & A^{-1}
\end{array}\right]\left[\begin{array}{l}
\hat{\beta}_{i}^{*} \\
\hat{a}_{i}^{*}
\end{array}\right]=\left[\begin{array}{l}
0 \\
0
\end{array}\right] \text {, }
$$

which leads to $\hat{\mathbf{a}}_{i}{ }^{*}=0$ and indefinite $\hat{\boldsymbol{\beta}}_{i}{ }^{*}$. The solutions on the original scale are given by the backtransformation, as follows

$$
\hat{\mathbf{a}}=\left(\mathbf{Q} \otimes \mathbf{I}_{p}\right) \hat{\mathbf{a}}^{*} \text {. }
$$

\section{Ranks of the key matrices and the numbers} of positive eigenvalues

Since $\mathbf{H}_{0}$ is a symmetric and positive semidefinite matrix, its eigenvalues are all nonnegative, and the number of the positive eigenvalues is equal to its rank. From the notion of rank, rank of the product of a matrix and a non-singular matrix equals rank of the former matrix. So, the rank of $\mathbf{H}_{0} \mathbf{R}_{0}$ is the same as that of $\mathbf{H}_{0}$. Because of

$$
\left(\mathbf{H}_{0} \mathbf{R}_{0}\right)^{2}=\mathbf{H}_{0} \mathbf{R}_{0},
$$

or $\mathbf{H}_{0} \mathbf{R}_{0}$ is idempotent, the rank of $\mathbf{H}_{0} \mathbf{R}_{0}$ becomes

$$
\begin{aligned}
\operatorname{rank}\left(\mathbf{H}_{0} \mathbf{R}_{0}\right) \\
\quad=\operatorname{rank}\left[\mathbf{I}-\mathbf{R}_{0}^{-1} \mathbf{G}_{0} \mathbf{T}_{0}\left(\mathbf{T}_{0}{ }^{\prime} \mathbf{G}_{0} \mathbf{R}_{0}^{-1} \mathbf{G}_{0} \mathbf{T}_{0}\right)^{-1} \mathbf{T}_{0}{ }^{\prime} \mathbf{G}_{0}\right] \\
\quad=q-\operatorname{rank}\left(\mathbf{T}_{0}\right) \\
\quad=q-r+1 .
\end{aligned}
$$

Therefore, the number of positive eigenvalues of $\mathbf{H}_{0}$ is expressed as $q-r+1$. Using Sylvester's law of inertia, the number of positive eigenvalues of a matrix is not altered by multiplying a non-singular matrix. Consequently, the number of positive eigenvalues of $\mathbf{G}_{0} \mathbf{H}_{0}$ is given as $q-r+1$, which is the rank of $\mathbf{H}_{0}$. From this consideration, the number of positive eigenvalues concerning eq. (8) depends on the rank of $\mathbf{H}_{0}$, and the number of sets of eq. (9) to be solved becomes $q-r+1$.

\section{Discussion}

After Mallard's work ${ }^{9)}$, it is well known that Kempthorne and Nordskog's restricted selection index method ${ }^{8)}$ (and thus Quaas and Henderson's restricted BLUP procedure ${ }^{103}$ ) can handle the cases of proportional constraints or relatively desired gains on traits. According$l y$, as described in this paper, RBLUP $\mathrm{CT}^{7}$ is also a general procedure and is straight- 
forwardly applicable to the situations of proportional constraints considered. Hence, the originality of this paper on the aspect of describing the outline of the PRBLUP CT procedure might be scarce, but it could be of certain value to have examined here the nature of ranks and the numbers of positive eigenvalues of the key matrices, and the number of independent systems of equations to be solved in the procedure with proportional constraints considered. In this context, this paper is a supplement to Itoh and Iwaisaki ${ }^{7}$. We have not provided a numerical illustration on the current procedure. Except for the construction of an appropriate $\mathbf{T}_{0}$, however, one may make reference to the worked example given by Itoh and Iwaisaki ${ }^{7}$.

For the case of zero restrictions with canonical transformation applied, the eigenvalues which are the diagonal elements of the diagonal matrix $\mathbf{D}$ in the transformation can become zero as a result of putting the restrictions. The number of equation systems to be solved is dependent upon the number of the restricted traits and is $q-r^{7}$. Similarly for the corresponding cases of proportional constraints, or PRBLUP CT, the number of the equation systems to be solved is affected by the number of non-zero eigenvalues of the product of $\mathbf{G}_{0}$ and the constraint-imposing matrix $\mathrm{H}_{0}$ which corresponds to the rank of $\mathbf{H}_{0}$. Although as the number of proportionally restricted traits becomes high, that of the equation systems to be solved becomes low, the actual number of the equation systems in the PRBLUP CT is not completely the same as that in the RBLUP CT. Converting relatively desired gains into zero gain constraints of linear combinations of the traits, the number of positive eigenvalues and consequently that of the equation systems to be solved in PRBLUP CT results in $q-r+1$. Note that each system of equations for the transformed variables is solved separately as a single-variable analysis. When one wishes to achieve relatively desired gains in all the traits, or in the case of $q=r$, the rank of $\mathbf{H}_{0}$ is unity and only one system of equations for the single variable is needed to solve, in which the computational burden would be largely reduced. In this case, the final solutions backtransformed are proportional to each other for all the traits within each animal, because of $\mathbf{T}^{\prime} \mathbf{a}=\mathbf{0}$, similarly as demonstrated by Quaas and Henderson ${ }^{10)}$.

The computation of the $\mathbf{A}$ matrix which is involved in eq. (4) as $\mathbf{G}=\mathbf{G}_{0} \otimes \mathbf{A}$, relatively compared to that of its inverse, is very time consuming with a large number of animals to be evaluated. Then Quaas and Henderson ${ }^{\text {10) }}$ showed that it is possible to eliminate $\mathbf{A}$ from eq. (4). The (P) RBLUP CT procedures also do not require $\mathbf{A}$. In addition, an advantage of the procedures is that the transformation matrix $\mathbf{Q}$ can easily be obtained using a general program package and then, without requiring any special computing program for (P) RBLUP, eq. (9) corresponding to the positive eigenvalues can be solved utilizing a conventional program written for a single-trait BLUP.

However, the use of the (P) RBLUP CT procedures requires the following conditions: 1 ) animal models, 2) no other random factors except for animals and residuals, 3) no partially missing records, and 4) for all traits the same design matrices concerning fixed effects. For these conditions, finally, we would like to comment that an animal model is becoming the predominant model in current systems for genetic evaluation, and that following some recent findings ${ }^{2,3}$, it might be possible to extend the procedures to the situations where the above conditions 2) to 4) are relaxed.

\section{References}

1) Brascamp EW. Selection indices with constraints. Anim. Breed. Abstr., 52 : 645-654. 1984.

2) Ducrocq V, Besbes B. Solution of multiple trait animal models with missing data on some traits. J. Anim. Breed. Genet., 110 : 81-92. 1993.

3) Gengler N, Misztal I. Approximation of reliability for multiple-trait animal models with 
missing data by canonical transformation. J. Dairy Sci., 79 : 317-328. 1996.

4) Henderson CR. Sire evaluation and genetic trend. In : Anim. Breed. Genet. Symp. in Honor of Dr. JL Lush. 10-41. ASAS and ADSA, Champaign IL. 1973.

5) Henderson CR. Applications of linear models in animal breeding. Univ. of Guelph Press. Guelph. 1984.

6) Itoh Y, Yamada Y. Comparisons of selection indices achieving predetermined proportional gains. Genet. Sel. Evol., $19: 69-82.1987$.
7) Itoh $Y$, Iwaisaki H. Restricted best linear unbiased prediction using canonical transformation. Genet. Sel. Evol., 22 : 339-347. 1990.

8) Kempthorne $\mathrm{O}$, Nordskog AW. Restricted selection indices. Biometrics, 15 : 10-19. 1959.

9) Mallard J. La theorie et le calcul des index de selection avec restrictions : synthese critique. Biometrics, 28 : 713-735. 1972.

10) Quaas RL, Henderson CR. Restricted best linear unbiased prediction of breeding values. Mimeo, Dept. Anim. Sci., Cornell Univ., Ithaca NY. 1976.

\title{
正準変換を利用した比例制限付きBLUPにおける 連立方程式系の特徵
}

\author{
高橋 毅* ・祝前博明 ${ }^{1} \cdot$ 伊藤要二 2 \\ 新潟大学大学院自然科学研究科, 新渴市 950-2102 \\ 1 新潟大学農学部, 新潟市 950-2102 \\ ${ }^{2}$ 大塚製薬(株)生物統計解析室, 大阪市中央区 540-0021
}

\begin{abstract}
本論文では，正準変換を利用したいわゆるゼロ制限に関する制限付き BLUP 法 (RBLUPCT) が，育 種洒の比例制限付きBLUPに対してどのように応用され得るかを示すとともに，記述された手法 （PRBLUP CT）においてキーとなる行列のランクおよび正の固有值数に関する性質を調べることによ り，解くべき連立方程式系の特徴を明らかにした。多形質個体モデルにおける評值対象形質数を $q$, 制限 付与形質数を $r$ とすれば，RBLUP CT に扔ける独立な連立方程式系の個数は $q-r$ であるのに対して， PRBLUPCTに捛けるそれは $q-r+1$ として与えられた，すなわち，r加増加すれば，応じて解くべき連 立方程式系の個数纺逆に隇少し，例えばすべての形質に対して此例制限を付与する場合にはキー行列の ランクおよび正の固有值数は 1 となり，通常の単一形質BLUP に関する一組の連立方程式系のみを解 けばよいことが示された。
\end{abstract}

\footnotetext{
* 現所属 : 全国和牛登録協会兵庫県支部，神戸市中央区 $650-0004$
} 